\title{
The diversity of intertidal fish in Sundak Beach, Yogyakarta, Indonesia, during dry and rainy seasons
}

\author{
Ratih Ida Adharini", Namastra Probosunu, Atika Arifati, Tika Drastiana, and Fitriana C. \\ Rusnasari \\ Department of Fisheries, Faculty of Agriculture, Universitas Gadjah Mada, Yogyakarta, Indonesia. \\ Building A4 Jl. Flora Bulaksumur, Yogyakarta 55281, Indonesia. Tel/Fax +62-274-551218,
}

\begin{abstract}
The intertidal zone is a transition area between sea and land with unique characteristics. This research aimed to determine the diversity and types of fish in the intertidal zone of Sundak Beach, Yogyakarta, Indonesia. This research was conducted in December 2016-September 2017 along the intertidal zone of Sundak Beach. Fish samples were collected by fishermen twice a month using a hand net and hand line in an area of $22,000 \mathrm{~m}^{2}$ by random sampling. Water quality data included air and water temperatures, $\mathrm{pH}$, salinity, tides, rainfall intensity, and substratum. Fish samples were identified, and the total length and weight were measured. Results showed that carnivores and herbivores were dominant during the rainy season, whereas carnivores and omnivores were dominant during the dry season. Total of 179 fish, which were grouped into 18 families and 31 species. The diversity species index was 1.067 (intermediate diversity) during the rainy season but 0.19 (low diversity) during the dry season. The dominancy index was low $(0.11-0.34)$ during the dry season, whereas during the rainy season was higher (0.18-0.72). The study concluded that the intertidal zone of Sundak Beach has a good condition as nursery, feeding, and spawning grounds for fishes.
\end{abstract}

\section{Introduction}

Indonesia is a country with the fourth longest coastline in the world, and it is rich in resource potential and biodiversity. However, its biodiversity will be easily deteriorated and lost if the natural resources are not properly protected and managed. An important step in the protection and management of biodiversity is by making an inventory of our existing biodiversity in order to support the stability and resiliency of our ecosystem.

Sundak Beach is one of the beaches from the coastal cluster along the south coast of Yogyakarta, and it directly faces the Indian Ocean. It has two seasonal variations, namely, rainy and dry seasons. As a tropical intertidal zone, the temperature of the waters is usually

\footnotetext{
* Corresponding author: ratih.adharini@ugm.ac.id
} 
warmer and it is also a thriving habitat for communities of organisms, such as intertidal fish, aquatic invertebrate, birds, and seaweed in the area. Zabin et al. [1] stated that intertidal zones in tropical regions or low-latitude areas have higher species diversity compared with intertidal zones in high-latitude regions. Sundak Beach has a rocky substrate that comprises corals and dead corals. It also features rock pools, which are bordered by white sand, and a vast expanse of seaweed beds. The structural complexity of rockpool habitats plays an important role in supporting species richness and preserving local fish diversity [2]. Furthermore, the community structure of tide pools is related to pool size for species permanency, cover for avoiding predatory species, and ecological effects (e.g., competition, territoriality, and predation) [3]. Sundak Beach is also a major tourism destination, and many tourists come to visit and explore this beach. The tourism activities, directly and indirectly, affect ecosystem changes, including the biodiversity of intertidal fish in Sundak Beach. Cunha et al. [4] reported that tourism has a major effect on decreasing abundance and biodiversity.

The intertidal zone is an area that is highly vulnerable to ecosystem changes. These changes can be affected by natural causes or by anthropogenic factors. Therefore, organisms that live in high intertidal regions must be able to cope with the fluctuating conditions [5]. Seasonal conditions greatly affect the physical, chemical, and environmental biology of the intertidal zone. Such environmental changes then influence the trophic structure of the intertidal ecosystem. Furthermore, these changes, directly and indirectly, impact the abundance and diversity of intertidal fish and their supporting factors. The ecological complexity and environmental changes in intertidal habitats are also strongly influenced by tide cycles [6]. Richness and diversity increase from high to middle elevation but remain the same between middle to low elevation, because abiotic stress is higher at high elevation than at middle and low elevation [7]. Furthermore, Craig et al. [8] reported that ocean condition may influence larval rockfish survival, movement patterns, and habitat usage.

The complexity and dynamics of the intertidal fish community are attributed to the differing time periods of various species that spend their lives in the rocky shore habitat [9]. Intertidal fishes were divided into permanent residents (fish that spend their life history in the intertidal zone), temporary/opportunistic (fish that spend part of their lives in the intertidal zone, and transient (fish that are occasionally present in the low rock pool) $[10,11]$. The present research aimed to determine the diversity of intertidal fish during dry and rainy seasons and study the types of intertidal fish in Sundak Beach. The results are expected to be used as a basis for coastal and sustainable management of fishery resources via ecological approaches.

\section{Materials and Methods}

\subsection{Study sites}

This research was conducted by random sampling from December 2016 to September 2017 in the intertidal zone of Sundak Beach, Yogyakarta, Indonesia, which comprised an area of $22,000 \mathrm{~m}^{2},\left(\mathrm{~S}^{\circ} 8^{\prime} 49^{\prime \prime} \mathrm{E} 110^{\circ} 36^{\prime} 28^{\prime \prime}\right)$ was dominated by the substrate of sand, rock, and reef. 


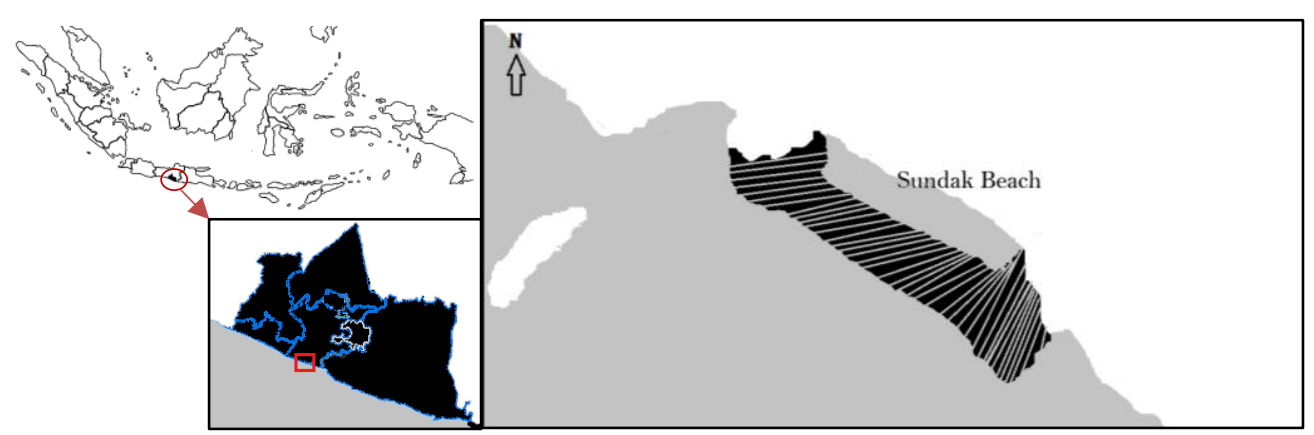

Fig. 1. Study sites in intertidal zone of Sundak Beach, Yogyakarta, Indonesia

\subsection{Observation of intertidal fishes}

Fish were collected using a hand net and hand line. All fish samples were kept in an icebox and then brought to the laboratory. Fish samples were preserved in $70 \%$ alcohol and seawater then froze in a refrigerator. Total length was measured using calipers $(0.1 \mathrm{~mm})$ and a digital weighing scale $(0.01 \mathrm{~g})$. Fish samples were identified using taxonomic keys relevant to the region $[12,13]$. Life-history stages of all species were determined by using the minimum length of maturity for each species (Fishbase, 2017) and dividing the length range into two groups: juvenile and adult. For data analysis, fish were categorized into three tropic groups: herbivore, carnivore, and omnivore [14]. Community structure indices included ShannonWiener index diversity $\left(\mathrm{H}^{\prime}\right)$ and domination index (D) [15]. Fish samples were categorized as resident or transient following previously published works [11] and Fishbase.

\section{Results and Discussion}

Table 1. The number of individuals and species of intertidal fishes collected in Sundak Beach during the dry and rainy seasons.

\begin{tabular}{llcccc}
\hline \multirow{2}{*}{ Family } & \multicolumn{1}{c}{ Species } & \multicolumn{2}{c}{ Number of Individuals } & \multirow{2}{*}{ Total } & $\begin{array}{c}\text { Fish } \\
\text { categorized }\end{array}$ \\
\cline { 3 - 5 } Acanthuridae & Acanthurus triostegus & 6 & 0 & 6 & Transients \\
Apagonidae & Ostorhinchus nigrofasciatus & 3 & 0 & 3 & Transients \\
& Ostorhinchus relativus & 17 & 1 & 18 & Transients \\
Blennidae & Entomacrodus marmoratus & 5 & 2 & 7 & Resident \\
& Entomacrodus thalassinus & 2 & 1 & 3 & Resident \\
& Entomacrodus vemiculatus & 3 & 0 & 3 & Resident \\
Carangidae & Carangoides malabaricus & 3 & 0 & 3 & Transients \\
Cirrhitidae & Cirrhitus pinnulatus & 1 & 0 & 1 & Transients \\
Eleotridae & Oxyeleotris uropthalmus & 0 & 1 & 1 & Transients \\
Ephippidae & Platax orbicularis & 9 & 10 & 19 & Transients \\
Gerreidae & Gerres limbatus & 2 & 0 & 2 & Transients \\
Holocentridae & Myripristis pralinia & 1 & 0 & 1 & Transients \\
& Myripristis pralinia & 4 & 0 & 4 & Transients \\
Labridae & Gomphosus varius & 6 & 0 & 6 & Transients \\
& Halichoeres miniatus & 2 & 0 & 2 & Transients \\
& Halichoeres nigrescens & 12 & 0 & 12 & Transients \\
& Halichoeres & 0 & 4 & 4 & Transients \\
& pardaleocephale & 1 & 0 & 1 & Transients \\
\hline
\end{tabular}




\begin{tabular}{|c|c|c|c|c|c|}
\hline Megalopidae & Megalops cyprinoides & 1 & 0 & 1 & Transients \\
\hline Mugilidae & Moolgarda cunnesius & 0 & 1 & 1 & Transients \\
\hline \multirow{2}{*}{$\begin{array}{l}\text { Pinguipedidae } \\
\text { Polynemidae }\end{array}$} & Parapercis clathrata & 1 & 0 & 1 & Transients \\
\hline & $\begin{array}{l}\text { Elentheronema } \\
\text { tetradactylum }\end{array}$ & 25 & 0 & 25 & Transients \\
\hline \multirow[t]{5}{*}{ Pomacentridae } & Abudefduf septemfasciatus & 0 & 11 & 11 & Transients \\
\hline & Abudefduf sordidus & 2 & 0 & 2 & Transients \\
\hline & Chrysiptera glauca & 1 & 0 & 1 & Transients \\
\hline & Stegastes albifasciatus & 1 & 1 & 2 & Transients \\
\hline & Stegastes fasciolatus & 5 & 0 & 5 & Transients \\
\hline \multirow[t]{2}{*}{ Scorpaenidae } & Parascorpaena aurita & 0 & 1 & 1 & Transients \\
\hline & Parascorpaena picta & 6 & 21 & 27 & Transients \\
\hline Siganidae & Siganus doliatus & 2 & 0 & 2 & Transients \\
\hline \multirow[t]{2}{*}{ Teraponidae } & Terapon jerbua & 4 & 0 & 4 & Transients \\
\hline & Total & 125 & 54 & 179 & \\
\hline
\end{tabular}

The dry and rainy seasons affect the presence, abundance, and diversity of intertidal fish in Sundak Beach. In general, the abundance and diversity of intertidal fish in the rainy season are higher than those in the dry season. In the rainy season, 15 families and 26 species of intertidal fish species were found, whereas eight families and 11 species of intertidal fish species were noted in the dry season. The Labridae, Blennidae, and Pomacentridae families were the families most commonly found in Sundak Beach (Table 1). This observation was in accordance with the opinion of Roberts and Ormond [16], who stated that the Labridae family can live in extensive survival habitats, hence it is easily found in intertidal areas. Another report on the tropical intertidal zone of Los Cóbanos, El Salvador, found that Gobiidae and Pomacentridae exhibit high abundance and diversity [6]. Meanwhile, Blennidae and Gobidae are dominantly found in the rocky intertidal habitats of the Persian Gulf and the Gulf of Oman as resident fish [11]. Blennidae and Gobiidae also dominate the intertidal rock pools of Goa, west coast of India [17], the intertidal zone of New South Wales region, Australia [2], the natural reserve of Glorieuses Island, Western Indian Ocean [18], and Watamu Marine National Park of Kenya (2015). Gobiid fish are reported to have high tolerance due to environmental stress than other fish species [11]. Moreover, their small size allowed them to cope with fluctuating and extreme conditions [2]. Gobiidae and Blennidae are tolerant under abiotic and biotic pressure [19]. Almost all families found in the intertidal zone of Sundak Beach were categorized as transient fish, except Blennidae, which was classified as resident fish (i.e. Entomacrodus marmoratus, Entomacrodus thalassianus, and Entomacrodus vemiculatus; Table 1).
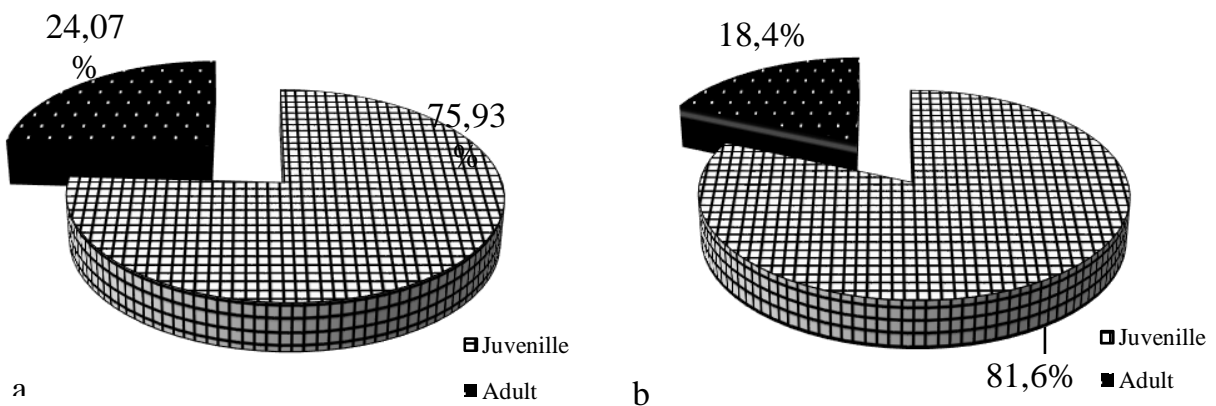

Fig. 2. Life stages of intertidal fish during dry (a) and rainy (b) seasons. 
Intertidal fish found in Sundak Beach were dominantly still in the juvenile stage during dry and rainy seasons (Fig. 1). Families dominantly found in the adult stage in the dry season were Blennidae and Scorpaenidae. By contrast, families that were found in juvenile and adult stages were Pomacentridae and Labridae. Families found in the rainy season were mostly still in the juvenile stage, whereas families found in juvenile and adult stages were Pomacentridae, Blennidae, Pinguippedidae, and Apagonidae. Blennidae were found in the adult stage in the dry season but in juvenile and adult stages in the rainy season. Blennidae spends their whole life cycle in the intertidal zone, so they are categorized as resident fish (Table 1). White et al. [2] found that resident families, which are easily found in the upper zone, reduce the risk of predation and interspecific competition; moreover, additional resources can be found in the upper zone. Nevertheless, almost all families found in the intertidal zone of Sundak Beach were categorized as transient fish (Table 1) and mostly found in the juvenile stage, but some adults were observed. These findings further emphasize the important role of the intertidal zone in marine ecosystems as a spawning ground, nursing ground, and feeding ground areas. Furthermore, intertidal habitats play an important role in the life cycle of reef fish species, which use intertidal ecosystems for reproduction, shelter to avoid predators, and foraging [20]. Therefore, disturbances and damage to habitats in the intertidal zone will exert a major impact on the reef fish community.

Several families only found during the rainy season, dry season, or both. The families that were commonly found in the rainy season were Acanthuridae, Blennidae, Polynemidae, Labridae, and Apagonidae, whereas the families that were commonly found in the dry season were Scorpaenidae and Pomacentridae. The species that were found during both the rainy and dry season were Ostorhinchus relativus, E.marmoratus, Entomacrodus thalassinus, Platax orbicularis, and Parascorpaenapicta.
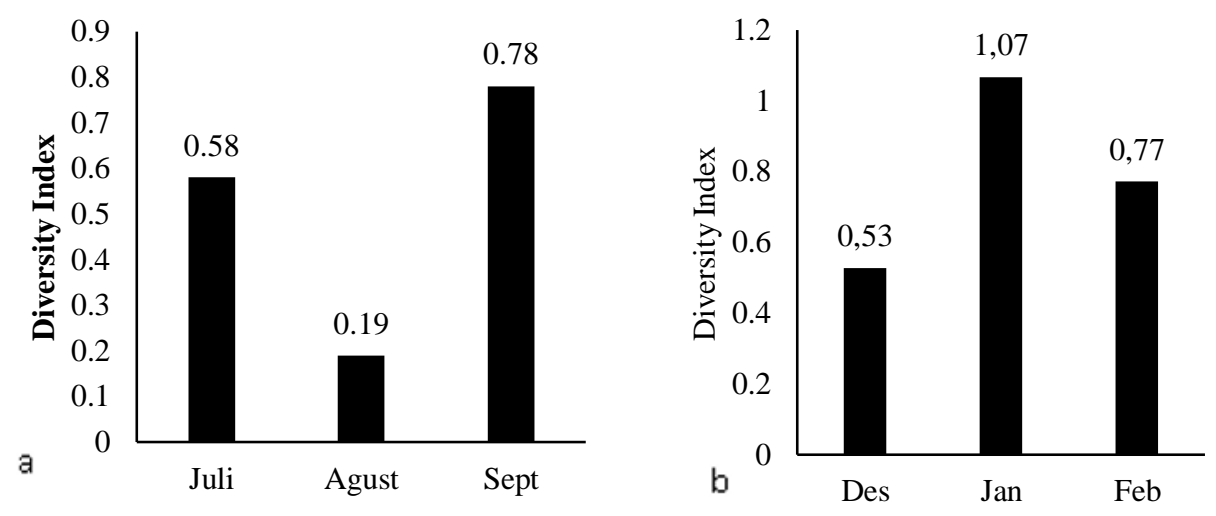

Fig. 3. Fish diversity (Shannon-Wienerindex) of intertidal fish in Sundak Beach during dry (a) and rainy (b) seasons.

The intertidal fish diversity index in the rainy season was higher $(0.53-1.07)$ than that in the dry season $(0.19-0.78)$. The highest diversity index in the rainy season occurred in January at 1.07 , which was considered moderate diversity. The lowest diversity index in the dry season occurred in August at 0.19, which was categorized as low diversity. 

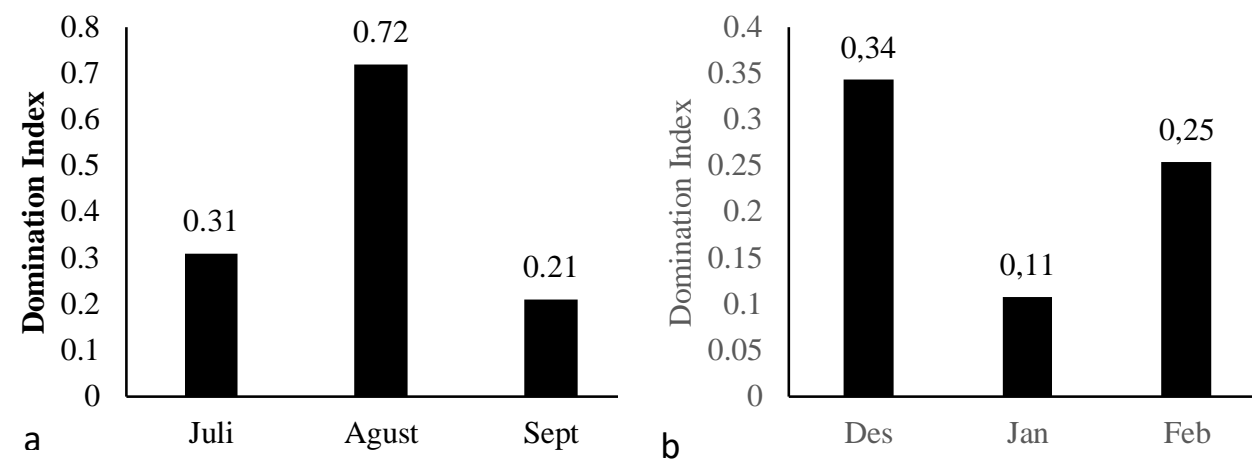

Fig. 4. Dominance index of intertidal fishes in Sundak Beach during dry (a) and rainy (b) seasons

The high fish diversity in January is followed by a low dominance index in January (0.11). A high dominance index in December (0.53) occurred when the fish diversity index is low because high diversity will reduce competition and species dominancy. Species dominantly found in the dry season are P. picta and Abudefduf septemfasciatus. By contrast, species dominantly found in the rainy season are O.relativus, Elenthero nematetradactylum, and Halichoeres nigrescens. Roberts and Ormond [16] found that species variety increases with increasing depth.
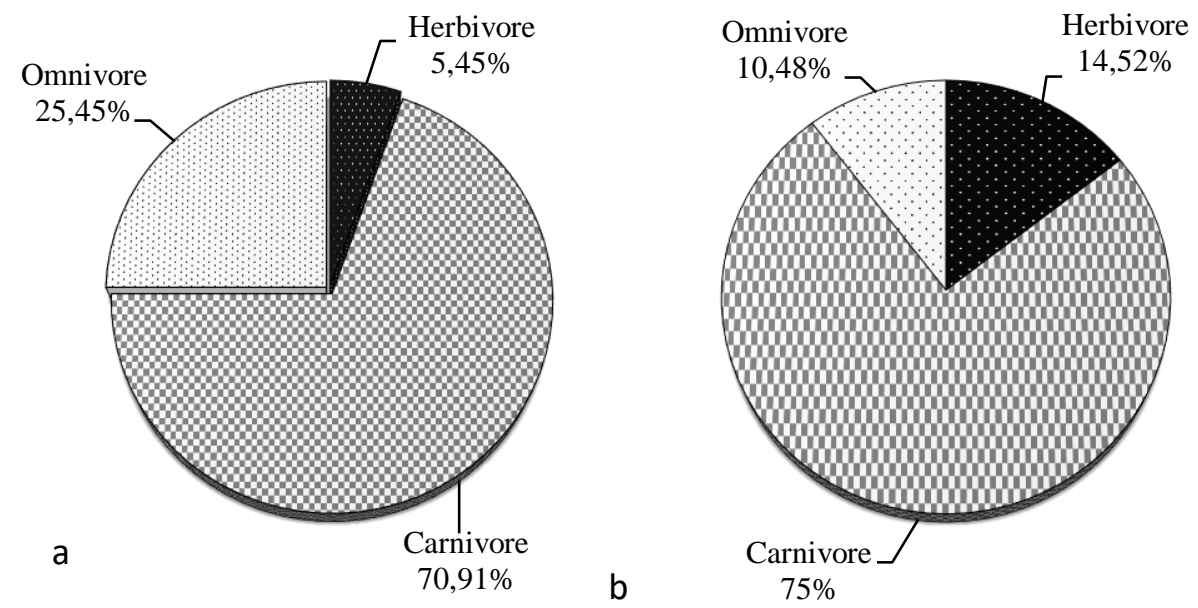

Fig. 5. Trophic structure of intertidal fishes in Sundak Beach during dry (a) and rainy (b) seasons.

The trophic structure of intertidal fishes in Sundak Beach in dry and rainy seasons was dominated by carnivore species. This result was also strengthened by Andrades et al. [19], who found that coastal regions are dominated by carnivore species, whereas the oceanic zone is dominated by herbivore species. The proportion of herbivore species in Sundak Beach during the rainy season was bigger than that in the dry season, possibly because the abundance of seawater and seaweed in the rainy season drives phytoplankton to thrive. This result was strengthened by Lee et al. [21], who reported that herbivores, carnivores, and piscivorous increased during tidal floods, but detritivores decrease. Meanwhile, in the dry season, the proportion of herbivorous species in Sundak Beach decreases, followed by an increase in omnivorous. In the dry season, phytoplankton and seaweed become limited, so 
herbivorous species become omnivores. Horn and Martin [9] revealed that the dominant intertidal fish species are carnivores and omnivores, which consume benthic invertebrates (i.e., copepod, amphipod, decapod crustaceans, mollusks, and polychaetes) in the rocky intertidal habitat.

Table 2. Water quality in Sundak Beach, Yogyakarta, Indonesia, during the research period

\begin{tabular}{|c|c|c|c|c|c|c|}
\hline \multirow{2}{*}{ Parameter } & \multicolumn{3}{|c|}{ Rainy Season } & \multicolumn{3}{|c|}{ Dry Season } \\
\hline & December & January & February & July & Augustus & September \\
\hline \multicolumn{7}{|l|}{ Physical Parameters } \\
\hline Air Temperature $\left({ }^{\circ} C\right)$ & 27.5 & 28.5 & 27 & 29 & 29 & 28 \\
\hline Water Temperature $\left({ }^{o} C\right)$ & 31 & 30 & 31.5 & 30 & 31 & 32 \\
\hline Rainfall (mm) & $613^{* *}$ & $444 * *$ & $344 * *$ & $29 * *$ & $10 * *$ & $21 * *$ \\
\hline Substratum & \multicolumn{6}{|c|}{ Sand, Rock and Reef } \\
\hline
\end{tabular}

\section{Chemical Parameters}

\begin{tabular}{lcc}
\hline Salinity $(\mathrm{ppm})$ & $33-34$ & $30-36$ \\
$\mathrm{pH}$ & $7.0-7.6$ & $7.2-8.3$ \\
\hline
\end{tabular}

\section{Biological Parameters}

Associated Biota

Gastropoda, Sponge, Platyhelminthes, Echinodermata

Vegetation

Chlorophyta, Phaeophyta, Rhodophyta, and Seagrass

**: Data from Meteorology, Climatology, and Geophysics Institution (BMKG Indonesia)

Physical, biological, and chemical parameters play a major role in determining fish spatial occupancy [19]. Temperature is the greatest factor that influences marine fish distribution [22]. As a tropical region, the water temperature of the intertidal zone of Sundak Beach is relatively warm $\left(30{ }^{\circ} \mathrm{C}-32^{\circ} \mathrm{C}\right)$. During dry and rainy seasons, the water temperature at daylight is warmer than the air temperature. Salinity levels exhibit more fluctuations in the dry season than in the rainy season. Such fluctuations in the dry season may decrease the abundance and diversity of fish. Ghanbarifardi and Malek [11] reported that extreme environmental conditions in the Persian Gulf resulted in a significant reduction of faunal diversity due to high temperature and salinity. Similarly, the abundance and intertidal fish diversity in Sundak Beach decreased in the dry season.

In the rainy season when seawater is abundant, tide pools are submerged at both high and low tides. Therefore, the diversity and abundance of intertidal fish in the rainy season in Sundak Beach are more abundant than those in the dry season. Many residents and transient fish in juvenile and adult stages are easily found. By contrast, the abundance and biodiversity of intertidal fish are low at low-tide in the dry season. This finding may be correlated with adaptation and survival ability to cope with extreme conditions. This case was also found by Unsworth et al. [23], who demonstrated that abundance and diversity of fish assemblage are elevated at high tides than at low tides. The reduction in tides is also related to the reduction in fish abundance and diversity [8]. Zabin et al. [1] found that the gradient of wave exposure and distance from urban areas both affect species diversity.

The abundance and diversity of fish species are strongly affected by the biological diversity of the substratum [18]. Rocky intertidal zones with algal plant cover have large diversity and abundance of species [2,24,25]. Furthermore, the algal diversity in a rocky 
intertidal system corresponds with the animal diversity that uses the plant community for food and shelter [26]. The synergistic interaction of niche availability and ecological relationship among species form the fish community structure [3]. The intertidal zone of Sundak Beach is composed of white sand and rocky substrate, which comprises living and dead corals. On this rocky substratum, seagrass, and seaweed grow abundantly from classes of Chlorophyta, Phaeophyta, and Rhodophyta. Many organisms such as sponges, turbellarian flatworms, gastropods, bivalves, sea stars, brittle stars, sea urchins, and reef fish are symbiotic with one other, are easily found on seagrass and seaweed beds. This symbiosis is responsible for the stability of the intertidal ecosystems.

The fish diversity index in Sundak Beach, Yogyakarta during the dry season was categorized as low to medium, whereas that in the rainy season was medium. The Pomacentridae, Blennidae, and Labridae families demonstrated higher abundance and diversity than the other families. The ecology of Sundak Beach is still in good condition to support living organisms in the intertidal zone.

\section{References}

1. C.J. Zabin, E.M. Danner, E.P. Baumgartner, D. Spafford, K.A. Miller, and J.S. Pearse, Mar. Ecol. 1-26 (2012)

2. G.E. White, G.C. Hose \& C. Brown, Mar. Ecol. 36(4), 1332-1344 (2015)

3. R.M. Macieira \& J.C. Joyeux, Fish. Bull. 109:305-315 (2011)

4. E.A. Cunha, R.A.A. Carvalho, C. Monteiro-Neto, L.E.S. Moraes \& M.E. Araujo, Iheringia, Sér. Zool., Porto Alegre 98(3), 379-390 (2008)

5. J.G. Richards, J. Exp. Biol. 214, 191-199 (2010).

6. S. Gonzales-Murcia, F.C. Batres \& M.H. Lovo, Pan-Am. J. Aquat. 11(3), 227-242 (2016)

7. R.A. Scrosati, A.S. Knox, N. Valdivia \& M.Molis, Helgol Mar. Res. 65, 91-102 (2011)

8. S. Craig, J. Tyburczy, I. Aiello, R. Laucci, A. Kinziger, P. Raimondi, M. Minner, R. Gaddam, K. Ammann, M. George, L. Anderson, D. Lohse, M. Douglas, N. Fletcher, J.Lopiccolo \& K. Hinterman. Final Report: Baseline characterization of rocky intertidal ecosystems along the North Coast of California (2017)

9. H.M. Horn, M.H. \& K.L.M. Martin, Rocky intertidal zone. In: The ecology of marine Fishes and Adjacent Waters (University of California Press, Berkeley, 2006)

10. S.P. Griffiths, Estuar. Coast Shelf Sci. 58, 173-186 (2003)

11. M. Ghanbarifardi \& M. Malek, Mar. Biol. Res. 5, 496-502 (2009).

12. Allen, Marine Fishes of South East Asia (Periplus. Australia, 2000)

13. E. Carpenter, Kent, and V.H. Niem. FAO Species Identification Guide for Fishery Purposes the Living Marine Resources of the Western Central Pacific (Food and Agriculture Organization of the United Nations, Rome, 2001)

14. G.R. Allen, and M.V. Erdmann, Reef Fishes of the East Indies (Conservational International Indonesia. Bali, 2012).

15. E.P. Odum, Dasar-dasar Ekologi (Gadjah Mada University Press, Yogyakarta, 1996)

16. C.M. Roberts \& R.F.G. Ormond, Mar. Ecol. Prog. Ser. 41, 1-8 (1987)

17. L. Tsering, H.B. Pawar, R.A. Sreepada, S.V. Sanaye, U. Suryavanshi \& Tanu, Fish. Chimes, 32(8), 56-59 (2012)

18. P. Durville \& P. Cabanet, Western Indian Ocean J. Mar. Sci. 8(2), 225-230 (2009) 
19. R. Andrades, J.A. Reis-Filho, R.M. Macieira, T. Giarrizzo \& J.-C. Joyeux, Sci. Rep. 8, 10791 (2018)

20. V. Sindorf, B. Cowburn \& R.D. Sluka, Environ. Biol. Fishes, 98(3), 10.1007/s10641015-0397-1 (2015)

21. C. Lee, Y. Huang, C. Chung \& H. Lin, Zool. Stud. 53, 56 (2014)

22. W.M. Eschemeyer, R. Fricke, J.D. Fong \& D.A. Polack, Zootaxa 2525, 19-50 (2010)

23. R.K.F. Unsworth, R.K.F., J.J. Bell \& D.J. Smith, J. Mar. Biol. Assoc. U.K. 87, 12871296 (2007)

24. B. Marsh, T.M. Crowe, W.W. Siegfried, S. Afr. J. Zool. 13, 283-291 (1978)

25. A.U. Caro, S.A. Navarrete \& J.C. Castilla, PNAS, 107(43), 18528-18532 (2010)

26. R.J. Best, A.L. Chaudoin, M.E.S. Bracken, M.H. Graham, \& J.J. Stachowicz, Ecology 95(5), 1308-1322 (2014)

27. Anonim, Fishbase (http://www.fishbase.org, 2017) 